\title{
Inspection of Radiation Shielding Proficiency and Effect of Gamma-Ray on ESR, Thermal, and FTIR Properties of Modified Borate Bioglasses by $\mathrm{CuO}$
}

Amal Mosleh Madbouly ( $\sim$ basmala1811@gmail.com )

Nuclear and Radiological Safety Research Canter, Egyptian Atomic Energy Authority https://orcid.org/0000-0003-0835-2257

A.M. Abdelghany

National Research Centre, Egypt

H. M. Diab

National institute of standards (NIS), Egypt

F. M. Ezz-ElDin

Egyptian Atomic Energy Authority

\section{Research Article}

Keywords: shielding parameters, ESR, Bioactive glass, CuO, glass-dosimeter, Thermal annealing, FTIR

Posted Date: January 27th, 2022

DOI: https://doi.org/10.21203/rs.3.rs-1279683/v1

License: (c) (i) This work is licensed under a Creative Commons Attribution 4.0 International License. Read Full License 


\section{Abstract}

This research studied the various properties of copper oxide (CuO)-doped bioactive borate glasses extensively for their applications in different fields. The radiation shielding properties, such as gammaray, neutron, electron, and proton radiation shielding, were investigated. Further, the glasses' mass attenuation coefficients were measured with a $\mathrm{Nal}(\mathrm{TI})$ detector; their derivative gamma shielding parameters were studied theoretically with the Phy-X/PSD program. Every increase in the CuO \% increased the fast neutron $(\Sigma R)$ gamma attenuation and effective removal cross-sections. Additionally, mass stopping power (MSP) and projected range (PR) for protons and electrons delivered good results in the $10 \mathrm{KeV}-10 \mathrm{MeV}$ kinetic energy range, as computed by the SRIM code. Also, the free-radical densities were measured via electron spin resonance to estimate the absorbed doses during accidental irradiation. The extensive reduction of the dose detection threshold $(2 \mathrm{~Gy})$ required the estimation of the signal of the non-irradiated sample. This work also studied the effects of applied microwave power incidence and absorbed dose on Cu-containing borate bioglasses. Finally, the thermal annealing of the emerging peaks, which were due to the irradiation signal-to-noise ratio and energy dependence, was studied to estimate the stabilities of such peaks. This modified material is recommended to detect and monitor the gammaradiation dose because of its good dosimetric properties. Finally, regarding the presence of the two borate groups, triangular (BO 3 ) and the tetrahedrally coordinated (BO 4 ), in their definite and typical wavenumbers, the FTIR spectra displayed simplified vibrations that were close to those of many bioglasses. This paper provides complementary results for the authors previous research examined this glass for low photon dose measurements using luminescence characteristics .

\section{1- Introduction}

Glassy systems are essential in many applications, including laboratory equipment, optoelectronics materials, thermal insulators, reinforcement materials, and radiation shielding materials, owing to their exceptional chemical properties, such as high densities, high refractive indexes, high infrared (IR) transparencies, and superior gamma-ray shielding capabilities [1].

Owing to the widespread utilization of nuclear technology, the concept of nuclear radiation protection has recently attracted enormous attention. Radioactive gamma sources have also enjoyed increased utilization in different fields, including medicine, biological research, sanitization, and the industry. This type of radiation can ionize media and emit secondary charged particles via complex mechanisms. Because of the impending dangers of these radiations to people, the environment, and degradation-prone materials, it is critical to improve radiation shielding materials [2].

Some special types of glass materials were recently employed for radiation dosimetry via different physical methods $[3,4]$. The monitoring of the resonance absorption of microwave power by unpaired electron spins in a magnetic field is called electron spin resonance (ESR). Different authors have explored ESR [3-5] to identify transition-metal ions that exhibit many applications. ESR dosimetry is a determining quantitative measurement of the free radicals induced by radiation in certain materials. For intermediate 
and high-level dose standardizations, ESR dosimetry with alanine (amino acid) is employed [6]. Many researchers have studied new different materials that can be employed as ESR dosimeter materials $[7,8]$.

Bioglass is considered a base material for a new ESR dosimeter. The ESR dosimetry technique has been used to estimate radiation doses in the population due to many radiation accidents [9]. The lower detection limit of ESR dosimetry of tooth enamels is approximately 2 Gy [10], while the upper dose limit is $>10 \mathrm{Kg}$ [11]. Recent researchers have invested efforts to investigate the possibility of ESR dosimetry to lower the dose levels by chemically reducing induced ESR signals.

Borate glass is one of the famous glass-forming systems. It is considered an ideal and effective case in the IR spectroscopy of glass science. Boron, considered the smallest mass-forming element and exhibits the main vibrational signal that correlates with the glass network, arises in the mid-IR region over 500 $\mathrm{cm}^{-1}$. The vibrational modes of metal-ion sites, which are active below $\sim 600 \mathrm{~cm}^{-1}$, are considered isolated from the other network styles, i.e., in the far-IR region [12], because of boron's ability to alter its arrangement with oxygen between three $\left(\mathrm{BO}_{3}\right)$ and four $\left(\mathrm{BO}_{4}\right)$. It supplies the anionic environment domain that could regulate the changeable metal ions. Therefore, the frameworks of bioactive borate glass, which exhibits a short-range, are being considered models for examining the IR region to arrange the structure of the network located at the mid-IR and the intuitive metal-ion location within the spectrum of the distant IR region. It is well-known that Cu particles are distributed within the glass network via several valance states, such as copper oxide (CuO (cuprous oxide and/or cupric oxide) and metallic copper $\left(\mathrm{Cu}^{+}\right)$owing to its electronic shells, which 3d104s1 represents. The colour of CuO-doped phosphate glasses generally depends on the $\mathrm{Cu}^{+2}$ particles, which induce defect centres through the adsorption band and visible regions. These defect centres can be modified. They can be diminished or expanded after determining the radiation-causing changes in the absorbance, supporting the production of a dosimeter from inactive glass. Furthermore, Cu particles can increase the ionic quality, and the glass network's electrical and optomechanical properties, by upgrading the glass matrix's homogeneity [13]. These characters avail information for utilizing $\mathrm{Cu}^{+}$-doped bioglasses as a glass dosimeter for a wide range of light dosages.

However, the increasing reputation of boron in recent years [14-17], particularly in radiation shielding applications, has prompted extensive research of the optical properties and radiation attenuation capabilities of the studied glasses. These explanations have yielded the creation of an $\mathrm{xBaO}$ (40$\mathrm{x}) \mathrm{Li}_{2} \mathrm{O} 0 \mathrm{~B}_{2} \mathrm{O}_{3}$ glass system, as well as the investigation of its optical and radiation shielding properties. It was hypothesized that barium oxide $(\mathrm{BaO})$ and lithium oxide $\left(\mathrm{Li}_{2} \mathrm{O}\right)$ substitutions would cause different behavioral changes in the optical and gamma-ray attenuation properties of the studied borate glasses. This study's findings can extend the literature on radiation shielding materials. Further, the authors believe that these findings will be beneficial to the scientific community by availing a basis for the further study of these materials regarding their mechanical and thermal properties and their durability.

The samples employed here were prepared by the same researchers in their previous work [3]. However, this study aims to investigate the radiation shielding efficiency of the prepared glasses within 
the photon energy range of $0.015-10 \mathrm{MeV}$, as well as the effective, fast neutron $\left(\Sigma_{R}\right)$ removal crosssections. Further, the ESR dosimetry technique in this study was compared with alanine dosimetry under the same conditions regarding their relative sensitivities. Furthermore, the sensitivities of the prepared samples compared with the alanine reference dosimeter in the gamma dose range of the intermediaterange were tested. Concurrently, a different technique other than ESR spectroscopy, i.e., Fourier-transform IR (FTIR), was achieved for radiation dose reconstruction.

\section{2- Experimental Work}

\section{1- Substances preparations}

The glass samples, a member of the Hench bioglass family with a nominal composition of $45 \mathrm{~B}_{2} \mathrm{O}_{3}-$ $24.5 \mathrm{Na}_{2} \mathrm{O}-24.5 \mathrm{CaO}-6 \mathrm{P}_{2} \mathrm{O}_{5}$, and other samples with the same compositions in which the CuO content attained $4 \mathrm{~g} /$ batch, were produced via the traditional melt annealing routine. The glass samples were prepared with chemically pure $\mathrm{H}_{3} \mathrm{BO}_{3}, \mathrm{CaCO}_{3}, \mathrm{Na}_{2} \mathrm{CO}_{3}$, and $\mathrm{NH}_{4} \mathrm{H}_{2} \mathrm{PO}_{4}$ that Raysan Chemicals supplied, as presented in Table 1. Further, calculated quantities of the prepared material were weighed before the material was melted in a Pt-2\% Rh ceramic container in a Vecstar induction melting furnace for $3 \mathrm{~h}$ at $1100^{\circ} \mathrm{C}$. The melts were rotated periodically to obtain homogeneous, glassy materials. Thereafter, the glass melt was cast into preheated molds exhibiting the required dimensions. The prepared glass samples were transferred immediately into the muffle furnace exhibiting an annealing temperature of $380^{\circ} \mathrm{C}$. After annealing for $1 \mathrm{~h}$ at a heating rate of $25^{\circ} \mathrm{C} / \mathrm{h}$, the annealing muffle was allowed to cool slowly to room temperature.

Table (1)

Chemical compositions and density for Glass samples.

\begin{tabular}{llllll} 
Sample & $\mathrm{B}_{2} \mathrm{O}_{3}$ & $\mathrm{Na}_{2} \mathrm{O}$ & $\mathrm{CaO}$ & $\mathrm{P}_{2} \mathrm{O}_{5}$ & $\mathrm{CuO}$ \\
\hline BGCu0 & 45.0 & 24.5 & 24.5 & 6.0 & 0.0 \\
\hline BGCu0.2 & 45.0 & 24.5 & 24.5 & 6.0 & 0.2 \\
\hline BGCu1.0 & 45.0 & 24.5 & 24.5 & 6.0 & 1.0 \\
\hline BGCu2.0 & 45.0 & 24.5 & 24.5 & 6.0 & 2.0 \\
\hline BGCu4.0 & 45.0 & 24.5 & 24.5 & 6.0 & 4.0
\end{tabular}

\subsection{Gamma-ray shielding properties}

The experimental linear attenuation coefficients (LAC) is determined by utilizing a gamma-ray spectrometer system which consists of $\mathrm{Nal}(\mathrm{TI})$ Scintillation detector (Oxford model) with 3" $\times 3$ ", amplifier 
and $16 \mathrm{k}$ multi-channel analyser as shown in Fig. (1) .

The $L A C\left(\mathrm{~cm}^{-1}\right)$ of all glass samples are calculated for gamma-rays of energies 662,1173 , and $1333 \mathrm{KeV}$ from radioactive point sources ${ }^{137} \mathrm{Cs}$ and ${ }^{60} \mathrm{Co}$, respectively. LAC can be evaluated by utilizing Brew Lambert's law equation [18], the mass attenuation coefficients MAC $\left(\mathrm{cm}^{2} / \mathrm{g}\right)$ are calculated for samples, by dividing $L A C$ by the density $(r)$ of the glasses samples $\left(\mathrm{g} / \mathrm{cm}^{3}\right)[19]$. Half value layer $(\mathrm{HVL})$, Mean free path (MFP), ), effective atomic number $\left(Z_{\text {eff }}\right)$, effective electron density $N_{\text {eff }}$, radiation protection

efficiency (RPE\%), electrical conductivity $C_{\text {eff }}$, effective removal cross-sections for fast neutrons $\left(\Sigma_{R}\right)$, and energy absorption build up factor have been estimated by Phy-X software. It is recommended to look at the reference $[20,21]$ with an explicit routine interpretation of all relevant equations. After that, for a description of the Phy-X/PSD software used [22].

\subsection{Gamma-irradiation regime}

The samples were exposed in batches to different gamma-irradiation doses from a Cs-137 source at the Laboratory of Ionizing Radiation Metrology, Egyptian National Institute of Standards (NIS). The irradiation of the batches was performed at a dose rate of $23 \mathrm{rad} / \mathrm{min}$. The calculated weight of the powdered bioactive borate glass sample was $100 \mathrm{mg}$ and that of the standard alanine pellet was $65 \mathrm{mg}$. The temperature and pressure of the samples were recorded before and after the irradiation by calibrated thermometer and parameter. The values from the readings of the absorbed dose were calculated employing an NPL electrometer exhibiting an ionization chamber (NE-2561) calibrated at the Bureau International Des Poids Et Measures (BIPM), France, with a combined uncertainty of $0.30 \%$. The calibration of the doses was indicated by air kerma (K air) at the International Atomic energy Agency, following a code of practice guide [23].

\subsection{Characterization}

An X-band ESR spectrometer (Bruker, EMX) was employed for the measurements by applying the standard rectangular cavity (4102ST) under operational conditions of $9.7 \mathrm{GHz}$ and a modulation frequency of $100 \mathrm{kHz}$. Briefly, $110 \mathrm{mg}$ of the borate glass samples were placed in a quartz tube $(3 \mathrm{~mm}$ i.d.). The height of the powdered sample inside the tube was $9-10 \mathrm{~mm}$, ensuring an identical cavity magnetic field. The microwave power was pre-selected to increase the "dosimetric signal point/natural signal point" ratio, while the "dosimetric signal point /low-frequency noise point" ratio decreased; thus, the microwave powers were 8,25 , and $50 \mathrm{~mW}$ for alanine and the bioactive glass, and the modulation amplitude was $4 \mathrm{G}$ for the bioactive glass. The center of the magnetic field sweeps was $3450 \mathrm{G}$, the sweep of the magnetic field was $4000 \mathrm{G}$, the field sweep rate was $100 \mathrm{G} / 82 \mathrm{sec}$, and the time constant value was $20 \mathrm{~ms}$. The scans of the field sweep were 10 and 30 in the intermediate-dose range. The receiver gain was $10^{4}$, and the spectrum resolution was 1024 . In order to calibrate the ESR intensity, the stability of the spectrometer besides the signal g-factor was used, and the MgO was impregnated 
separately with the Mn standard sample. An FTIR absorption spectrometer, such as the Bruker VERTEX 70 FTIR Spectrometers, was employed to measure the IR absorption spectra at room temperature in the 4000-400 $\mathrm{cm}-1$ range.

\section{3- Results And Discussion}

\subsection{Radiation shielding parameters}

The LAC values of the studied samples at photon energies of 662,1173 , and $1333(\mathrm{KeV})$ were measured on a gamma-ray spectrometer system. The Phy-X program obtained the theoretical results for the studied samples at the same photon energies are listed in Table 2. LAC is essential for evaluating glass materials' gamma-radiation attenuation shielding efficiencies. BGCu-4.0 exhibited the highest LAC value; however, as the energy increased, the LAC value decreased. Very small deviations, obtained in the LAC values obtained via experimental and theoretical methods, were typically caused by the small variations in the mathematical and physical models, the geometry, the atomic ambiguity, among other factors, for each method. Regarding all the glasses, the relative difference between the experimental method and PhysX/PSD increased from 0.49 to 2.01 .

\section{Table 2}

The experimental LAC $\left(\mathrm{cm}^{-1}\right)$ for bioactive borate glasses doped with copper oxide at different energies.

\begin{tabular}{|llllllllll|}
\hline Sample & \multicolumn{3}{l}{$662 \mathrm{KeV}$} & \multicolumn{3}{l}{$1173 \mathrm{KeV}$} & \multicolumn{3}{l|}{$1333 \mathrm{KeV}$} \\
\cline { 2 - 10 } & Exp. & Theo. & RD\% & Exp. & Theo. & RD\% & Exp. & Theo. & RD\% \\
\hline BGCu0 & 0.197 & 0.199 & 1.02 & 0.149 & 0.152 & 2.01 & 0.141 & 0.142 & 0.71 \\
\hline BGCu0.2 & 0.200 & 0.201 & 0.50 & 0.151 & 0.153 & 1.32 & 0.142 & 0.143 & 0.70 \\
\hline BGCu1.0 & 0.205 & 0.206 & 0.49 & 0.155 & 0.157 & 1.29 & 0.145 & 0.147 & 1.38 \\
\hline BGCu2.0 & 0.210 & 0.213 & 1.43 & 0.160 & 0.162 & 1.25 & 0.150 & 0.152 & 1.33 \\
\hline BGCu4.0 & 0.225 & 0.227 & 0.89 & 0.171 & 0.172 & 0.58 & 0.160 & 0.162 & 1.25 \\
\hline
\end{tabular}

The Phy-X software was used to calculate the radiation shielding parameters of the prepared glasses. Fig. (2) depicts the MAC results for study samples at photon energies ranging from 0.015 to $15 \mathrm{MeV}$. This figure shows that increasing the concentration of $\mathrm{Cu}$ increases the MAC while increasing photon energy decreases it because the interaction mechanisms of photons with matter differ depending on photon energies. With increasing photon energy, the probability of the photoelectric effect decreases, with the advantage of medium-energy Compton scattering and pair production dominance at high photon energies above 1.022 MeV [24].

Due to the high concentration of $\mathrm{Cu}$, the sample BGCu4.0 has the highest values of MAC at all energies when compared to the other studied glass samples at the same energy, where attenuation is dependent 
on the concentration, density of the elements in the matrix, and energy of the incident photons.

HVL can provide powerful insight into the shielding power of a sample as it reduces the number of photons in half by setting the desired thickness, thus providing a clear indication of the sample's shielding power. Figure 3 shows the HVL for the glasses. It can be seen that the HVL decreases as the $\mathrm{CuO}$ content increases. The GBCU4.0 sample with the highest concentration and density of CuO exhibited the highest absorbance of all samples tested. These results show that GBCU4.0 has the highest shielding efficiency against gamma rays as it has a higher MAC than other glasses studied. Here, the HVL value of BGCU4 is approximately $13 \%$ lower compared to the BGCU0 sample at $662 \mathrm{keV}$. Another important factor is the MFP, which accounts for the barrier's ability to reduce gamma rays. Thus, the glass with the lowest MFP shields well. The results show that as photon energy increases, so does the MPF of the glass (Fig. 4). This means that a large number of photons can pass through the glass at higher energies. It can also be seen that as the CuO content increases, the MFP value decreases significantly, which represent the average distance between two successive interactions of incident gamma photons. MFP value for studied BGCU4 glass appears to be small. Typically, because of the highest mass fraction of $\mathrm{Cu}$ in the tested glass than the other glasses samples.

A very relevant parameter, RPE\%, was calculated for all the glasses employing the experimental results and plotted as a function of the increase in the photon energy (Fig. 5). The RPE\% values varied from 18\% (for unfilled BGCu-0.0) and increased with the increasing Cu concentration from 18.2\% (BGCu-0.2) to $21 \%$ (BGCu4) at $662 \mathrm{keV}$. Additionally, the values of RPE\% increased by 2\% for BGCu-4.0 than BGCu-0.0 at 1173 and $1333 \mathrm{KeV}$. RPE\% decreased with the increasing energy for all tested energies [25].

This decreasing behaviour was because higher-energy photons easily penetrated the sample, thus reducing the number of photons attenuated by the glass shield and the RPE\%. These results also indicated that the BGCu-4.0 glass was more effective against lower-energy photons. Finally, the BGCu-4.0 sample exhibited the highest $\mathrm{CuO}$ content, making this glass the best choice for radiation shielding.

$\mathrm{Z}_{\text {eff }}$ is another essential factor that facilitates the determination of the attenuation capability of glass. Numerous studies have revealed that glass materials with high $Z_{\text {eff }}$ values demonstrate excellent radiation-protection potentials [26]. Fig. 6 shows the $Z_{\text {eff }}$ values of all the studied glasses in the $0.015-15$ $\mathrm{MeV}$ photon energy range. Clearly, $\mathrm{Z}_{\text {eff }}$ was affected by the photon energy and the changes in the chemical composition (e.g., the addition of $\mathrm{CuO}$ ) [27]. For all the glasses, larger values were observed in the lowest energy regions where the photoelectric effect predominates. In contrast, minimal values were observed in the medium-energy range due to the Compton scattering command and minor increments at higher energies due to the pair-production phenomenon's influence. As shown in Fig. 6, the BGCU-0.0 glass (without $\mathrm{CuO}$ ) exhibited the lowest $\mathrm{Z}_{\text {eff }}$ values, while the BGCU-4.0 glass (with $4 \mathrm{~mol} \% \mathrm{CuO}$ ) exhibited the highest $Z_{\text {eff }}$ values in the given photon energy range. Thus, the addition of $\mathrm{CuO}$ significantly increased the $Z_{\text {eff }}$ value. 
When a photon collides with an electron on glass material, it becomes a free electron. Moreover, a change in the number of free electrons would cause a change in the material's electrical conductivity. Glasses with varying conductivities based on their photon density and energy can change their shielding properties. Notably, the highest effective conductivity values were observed in the low-energy region because of the dominant photoelectric absorption there. The change in the effective conductivity was smaller in the high-energy region because the Compton scattering and pair-production processes dominated. Consequently, it is crucial to understand the $\mathrm{C}_{\text {eff }}$ coefficient, which demonstrates how glass retains its properties depending on the nuclear application. The $\mathrm{N}_{\text {eff }}$ and $\mathrm{C}_{\text {eff }}$ behaviours are identical to those of $Z_{\text {eff, }}$ as illustrated in Figs. 7 and 8. Fig. 9 shows the relationship between $Z_{\text {eff }}, N e f f$, and $C_{\text {eff. }}$

During the practical application of the prepared glass, particularly in radiation shielding, it is valuable to compare the protective properties of the prepared glass with those of some standard shields. Table 3 presents a typical comparison of the most crucial shielding parameters, including HVL, MFP, $Z_{\text {eff }}$ and $\mathrm{RPE} \%$, of BGCu- 4.0 and some shielding materials. The results demonstrated that the composite in this study exhibited a high shielding efficiency, which distinguished it from the other considered shielding materials.

Table 3

Comparison of many shielding parameters for the currently tested BGCU4 sample and various samples at $662 \mathrm{keV}$ gamma energy.

\begin{tabular}{llllll} 
Samples & HVL & MFP & MAC & $Z_{\text {eff }}$ & \\
\hline BGCU4 & 3.10 & 4.40 & 0.0788 & 5.3 & Present study \\
\hline Hematite-serpentine & 3.05 & 10.12 & 0.0787 & 9.98 & {$[28]$} \\
\hline PVC-H30 & 3.42 & 4.93 & 0.0795 & - & {$[29]$} \\
\hline Granite & 3.586 & 5.17 & 0.0738 & 10.02 & {$[30]$} \\
\hline Ba polymer concrete & 4.89 & 8.49 & 0.0720 & 10.16 & {$[31]$}
\end{tabular}

The absorption build-up factors are commonly used to describe gamma photon accumulation. The energy absorption build-up factor (EABF) indicates the number of photons accumulated within the thickness of the glass under consideration. The change in EABF with a photon energy range of $0.015-15$ $\mathrm{MeV}$, up to $40 \mathrm{mfp}$, is depicted in Fig. 10(a-d) for all glasses studied, and the dynamics of the EABF coefficient with energy is the same for all glasses. The dependence of EABF values on three parameters is shown in Fig. 10: the energy of the incoming gamma photon, the sample penetration depth in mfp, and the glass composition [18]. EABF was low at energies below $100 \mathrm{keV}$, gradually increasing up to $200 \mathrm{keV}$, then decreasing with increasing energy. First, when the photoelectric interaction almost completely eliminates the incident gamma photon, the calculated EABF values are lower. Following that, the number of photons heading up gradually increases as the interaction of Compton scattering increases. During the 
interaction, Compton scattering removes only a small fraction of the incident photon energy. Scattered photons, along with the rest of the incident photon energy, accumulated inside the investigated glass thickness. Pair production (PP) began to dominate for gamma photon energies above $1 \mathrm{MeV}$. As a result, the number of EABF values gradually decreased as the incident gamma photons increased.

Second, the calculated EABF values were observed to increase systematically with increasing penetration depth up to $40 \mathrm{mfp}$. Gamma photons take longer to penetrate the thicker layer, so more photons are accumulated. It is observed that the lowest EABF values are achieved at low penetration depths ( $1 \mathrm{mfp})$ while the highest EABF values are obtained at large penetration depths (40 mfp). The calculated EABF values decreased with increasing $\mathrm{CuO}$ content, while the minimum and maximum EABFs were obtained for 4 and $0 \mathrm{~mol} \% \mathrm{CuO}$. As the proportion of $\mathrm{CuO}$ content increased, the calculated EABF values increased. Therefore, the BGCU4.0 sample obtained the highest value with higher $Z_{\text {eff }}$ values, suggesting that it is an excellent shield for gamma rays.

It is widely known that neutrons have a greater radiobiological effect than photons, which require appropriate attenuators for the safety of radiation workers. In practice, neutron protection is achieved through scattering and absorption processes. For all glasses studied in Figure 11 shows the values of $\Sigma_{R}$. Obviously, $\Sigma_{R}$ values increase with increasing $\mathrm{CuO}$ concentration, indicating that $\mathrm{Cu}$ is effective $\Sigma_{R}$. Table 4 shows that the BGCU4.0 sample had higher $\Sigma_{R}$ values compared to the other nuclear shielding agents.

\section{Table 4}

Comparison of $\Sigma_{R}$ of glass BGCU4.0 with reported different nuclear radiation shielding substances.

\begin{tabular}{|lll|}
\hline Sample & $\Sigma_{R}$ & Reference \\
\hline BGCU4.0 & 0.114 & This work \\
Fluorophosphates glass S5 & 0.105 & {$[21]$} \\
$\mathrm{H}_{2} \mathrm{O}$ & 0.1024 & {$[33]$} \\
\hline TBBT30 glass & 0.1169 & {$[21]$} \\
\hline Ordinary concrete & 0.0937 & {$[28]$} \\
\hline Hematite-serpentine concrete & 0.0967 & {$[28]$} \\
\hline IImenite-limonite concrete & 0.0950 & {$[28]$} \\
\hline IImenite concrete & 0.1121 & {$[28]$} \\
\hline
\end{tabular}

\section{2-Electron spin resonance spectra}


Figs. 12(a-c) shows a standard comparison of the ESR line spectra of selected Cu-doped samples (a) before irradiation and (b) after being doped with $\mathrm{CuO}$ before the irradiation and after different gammairradiation doses ( 2 and $200 \mathrm{~Gy}$ ). The irradiated samples revealed a Gaussian-shaped ESR spectrum of the unirradiated sample at $g=2.0055$. It is evident from Fig. (12b) that the ESR spectrum of the $2 \mathrm{~Gy}-$ irradiated samples exhibited two signals, namely the radiation-sensitive and radiation-insensitive signals. Figs. (12b and c) show the ESR spectra of a sample comprising the anisotropic single sharp peak with values of $\mathrm{g}=1.9979$ and 2.0021 (maximum and minimum values of the signal at $\mathrm{g}=2.0037$ and 1.9979 , respectively). The signal corresponds to CuO [14-16]. Fig (12) shows the ESR spectra of the unirradiated and irradiated samples at 2 and $200 \mathrm{~Gy}$, respectively, with a magnetic field of $4000 \mathrm{G}$. This is considered a dosimetry signal; it exhibits a linearity property with the gamma-ray dose-response, i.e., the increase in the dose linearly increased the isotropic signal line.

It has been well established that adding a copper ion in a (BGCu-0.0) glass network would benefit the prospect of investigating the topical order via ESR spectroscopy [17]. $\mathrm{Cu}^{+}$and $\mathrm{Cu}^{2+}$ are the two soluble ionic states of $\mathrm{Cu}$ in glasses. At room temperature, $\mathrm{Cu}^{2+}$ is the only cause of ESR absorptions. $\mathrm{Cu}$ ions in the $\mathrm{Cu}^{2+}$ state are of the $3 \mathrm{~d} 9$ type, with $2 \mathrm{D}$ as the ground state, electron spin (S) of $1 / 2$, and nuclear spin (I) of $3 / 2$ for both 63Cu (natural abundance, 69\%) and 65Cu (natural abundance, 31\%) [34]. Although $\mathrm{Cu}$ ions are not visible during ESR absorption, they can interact with $\mathrm{Cu}^{2+}$. The increase in the dislocation of the glasses structure, dipole-dipole interactions, and interactions between ions in multivalent states all contribute to the expansion at $\mathrm{g}=1.977$. Thus, the presence of $\mathrm{Cu}^{2+}-\mathrm{Cu}^{+}$pairs and dipole-dipole interactions demonstrate the evolution of the ESR absorption line $(g=2.01)$ with the $\mathrm{CuO}$ material in the studied glasses. The g-factors and hyperfine constant values indicated that the bonding between $\mathrm{Cu}^{2+}$ and the ligand atoms was generally ionic [18], although there was a notable covalence consequence. Since $\mathrm{Cu}^{2+}$ is a network modifier, it competes with the borate network to form the cations for the oxygen pairs in their vicinity. Since the $\mathrm{B}-\mathrm{O}$ bonds in the cumulative system involving them are weakened, the covalence bonding between $\mathrm{Cu}^{2+}$ and $\mathrm{O}$ would increase. Generally, the signal amplitude is proportional to the number of ESR active centers that are involved in resonance absorption. Thus, the drop in the line amplitude of the $\mathrm{g}=2.1$ resonance at $40 \mathrm{kGy}$ indicated that the concentration of $\mathrm{Cu}^{2+}$ reduced the occurrence of diamagnetic $\mathrm{Cu}^{+}$, which coexists with $\mathrm{Cu}^{2+}$ in the glass network when the glass is subjected to irradiation $40 \mathrm{kGy}$.

\subsection{1- Microwave power dependence}

Fig. (13) indicates the dosimetric signal behavior of the samples irradiated to 200 Gy by Gamma rays (1 scan) based on the microwave power dependency. As shown by the figure, microwave power increased corresponded to a similar increase in signal intensity, which further increased exponentially before reaching saturation. A sufficiently high microwave power extending from 25 to $50 \mathrm{~mW}$ was optimal for these signal measurements. 


\subsubsection{Dose-response for gamma-ray}

The relation between the different Co- 60 gamma doses and the corresponding responses of the ESR signal intensities of bioglasses and alanine samples is shown in Fig. (14), showing that the CuO-doped bioglass sample exhibited excellent sensitivity, which was $~ 2.6$ times higher than those of alanine dosimeters. In the case of intermediate-dose range (2-200 Gy), a linear relationship appeared between the bioactive borate glass-absorbed dose samples and the first derivative line of the ESR peak-to-peak height.

\subsection{3-The energy dependency}

The energy dependence of the bioactive borate glass was studied by irradiating the different samples with the same dose (2 Gy) of different radiation energies. The ESR intensities at lower energies $(35,60$, and $80 \mathrm{KeV}$ of $\mathrm{X}$-ray) were higher than those at higher energies $\left({ }^{137} \mathrm{Cs}\right.$ and ${ }^{60} \mathrm{Co}$ ) (Fig. 15). Additionally, the photoelectric effect controlled the dose deposition from photon energy of $<100 \mathrm{KeV}$; in the case of higher energy, it was controlled by the Compton effect [35]. When alanine was irradiated, the stable free radicals, which might be measured directly, were evaluated [36].

\subsection{4- Signal to noise ratio}

Fig. 16 shows that the $\mathrm{S} / \mathrm{N}$ ratio of the modified borate glass was approximately 2.9 times higher than that of the alanine reference dosimeter under the same conditions, indicating the enhancement of the radiation sensitivity by the modified borate glass. This might be attributable to introducing $\mathrm{Cu}^{2+}$ in the glassy borate matrix that exhibited an enhanced radiation response.

\section{3-3-Thermal properties stability}

\section{3-3-1- Isochronal annealing Type}

Fig. 17 shows the temperature range for the isochronal annealing of the samples $\left(25^{\circ} \mathrm{C}-200^{\circ} \mathrm{C}\right)$ and the related relative intensity (n/no) of the dosimetric signal corresponding to a certain temperature. The figure indicated that the dosimetric signal was thermally stable at different annealing temperatures, thus reflecting the availability of this material for use in detecting and monitoring radiation dose.

\section{3-3-2-Isothermal annealing}

Fig. 18 shows the borate glass samples that were heated at different temperatures in a closed ESR tube. It shows the variations in the reciprocal intensity $(1 / n)$ after annealing as a function of the isothermal 
annealing time. Regarding the second-order decay, the results were plotted logarithmically. From the linear fitting slope, the lifetime of each annealing temperature of the glass sample could be evaluated.

Fig. 18 shows the isothermal annealing of borate glass as a function of time, obeying the second-order decay $(1 / n)$.

\subsection{3- Activation energy $E$ and lifetime $\rrbracket$ calculation}

Fig.19 Shows the reciprocal of Temperature (1000/T) versus $\otimes$ formula is called Arrhenius plot in semilogarithmic scale for borate bioglasses, activation energy calculation achieved by the equation ( $E=$ $0.1958 x$ slope) to be (19.58) ev. At $25^{\circ} \mathrm{C}$ and from the estimation of linear fitting of $r$ value versus the reciprocal temperature $(1000 / T)$ of the Arrhenius plot in a semi-logarithmic scale was utilized to calculate the lifetime $T$ and equal to $7 \times 10^{6}$ years.

\section{4- FTIR measurements}

\subsubsection{FTIR Absorption spectra of glass material before irradiation}

The FTIR absorption spectra of the studied glassy samples containing different concentrations of $\mathrm{Cu}$ ions were studied, and the wavenumber spectra versus absorbance were plotted (Fig. 20). The main absorption bands, which correlated with the $\mathrm{BO}_{3}$ and $\mathrm{BO}_{4}$ structural units, were observed and assigned. The soda-lime $-\mathrm{B}_{2} \mathrm{O}_{3}$ glass exhibited the characteristic IR spectra of combined triangular- and tetrahedraltype borate groups comprising the following spectral features:

1. Small broadband at $470 \mathrm{~cm}^{-1}$ usually combines with a kink near $530 \mathrm{~cm}^{-1}$.

2. A rounded peak with low intensity at $680 \mathrm{~cm}^{-1}$.

3. A broad middle curved band at $895 \mathrm{~cm}^{-1}$.

4. A broad strong band at $1030 \mathrm{~cm}^{-1}$.

5. A small peak at $1650 \mathrm{~cm}^{-1}$.

Borate glasses are fascinating solid materials because of their rich chemistry, as well as their capability of borate to easily vary its harmonic configuration with oxygen between three $\left(\mathrm{BO}_{3}\right)$ and four $\left(\mathrm{BO}_{4}\right)$ to form a changeable structural unit in some borate glasses [37]. Additionally, the results might be due to the small mass of boron atoms compared to those of other elements, such as $\mathrm{Si}, \mathrm{P}$, or Ge.

Furthermore, the appearance of the main IR vibrational modes related to the glass network was well above $500 \mathrm{~cm}^{-1}$ [38], clearly distinguishing them from those of the metal-ion sites, which are active in the 
far-IR region. Another IR study [39] of different borate glasses with a wide range of variable compositions was recorded via the $\mathrm{KBr}$ disk method.

The observed IR data were compatible with those of another reference IR spectral absorption measurement employing reflectance or transmission techniques [40]. The borate glass family, which originated from boron oxide $\left(\mathrm{B}_{2} \mathrm{O}_{3}\right)$, was synthesized by Zachariasen in 1932 [41] and is considered a glass former. Krogh-Moe [12] opined that borate glasses could be mainly formed from boron-oxygen triangles $\left[\mathrm{BO}_{3}\right]$, thus forming borax groups $\left(\mathrm{B}_{3} \mathrm{O}_{6}\right)$.

The observed parallelism between the IR spectra of the studied samples was due to some limitations regarding the vibrational bands, as follows:

i. A new band appeared in the middle region between 1400 and $1500 \mathrm{~cm}^{-1}$ with increasing intensities after doping with different $\mathrm{Cu}$ concentrations.

ii. The change feature of the near IR broadband intensity settled at $895-1030 \mathrm{~cm}^{-1}$.

iii. Some changes in the relative area of the main mid-two broad bands extended from 800 to 1200 $\mathrm{cm}^{-1}$ and 1250 to $1600 \mathrm{~cm}^{-1}$.

iv. The maintenance of the vibrational band around $3420 \mathrm{~cm}^{-1}$ was attributed to the water or $\mathrm{OH}$ vibrational groups even with the change in the copper content of the glassy matrix.

\subsubsection{FTIR Absorption spectra after irradiation}

It is accepted that [42] pure borate glass is created basically of $\mathrm{BO}_{3}$ as three-membered rings. When transition metal oxide (such as $\mathrm{CuO}$ ) is added to borate glass, $\mathrm{BO}_{3}$ triangles units transform to $\mathrm{BO}_{4}$ tetrahedral units, breaking bridging oxygen bonds to shape NBOs and populate the tetrahedral network interstitial sites of the locality of non-bridging oxygens which has a negative charge. Figure 10 proves no change in band positions with increasing $\mathrm{CuO}$ concentrations which confirmed both $\mathrm{BO}_{3}$ and $\mathrm{BO}_{4}$ structural unit formation. Such spectral data (Fig.21) indicate that there is no evidence for absorption band related to $\mathrm{CuO}$, simply it has affected the stability and shares of boron in many forming units. FT-IR representing the appearance of other forming units in the glass under investigation. The known FTIR absorption bands for different $\mathrm{B}_{2} \mathrm{O}_{3}$ at $\sim 720, \sim 1260$, and $\sim 1420 \mathrm{~cm}^{-1}$, which are concerning the vibrations $\mathrm{B}-\mathrm{O}$ bonds in $\mathrm{BO} 3$ units [42].

According to the vibrational modes of the borate glass matrix, it was divided into three infrared spectral ranges from 400 up to $4000 \mathrm{~cm}-1$. The location of the first group was found around $500 \mathrm{~cm}^{-1}$ throughout the region. These bands are due to the vibration of sodium cations in their oxygen sites [43], besides three characteristic bands for crystalline CuO were detected around $\sim 410, \sim 500$, and $\sim 610 \mathrm{~cm}^{-1}$, respectively, and where $\mathrm{Cu}_{2} \mathrm{O}$ was recognized around $615 \mathrm{~cm}^{-1}$. The second group of the spectrum is located in the region between 500 and $1450 \mathrm{~cm}^{-1}$ including the following bands $517,694,774,929,1014,1100,1240$, 
1320 , and $1400 \mathrm{~cm}^{-1} .$. These values are in accord with the analogous observation available in the literature [44], they are happened due to the vibrational style of the borate grid. The band noticed at 517 $\mathrm{cm}^{-1}$ is due to some deformation mode within the glass network, whereas the band noticed at $680 \mathrm{~cm}-1$ is related to the oxygen bridging two trigonal boron atoms (B-O-B) linkage in the borate matrix. The bands observed at 929,1014 and $1100 \mathrm{~cm}^{-1}$ are assuming $\mathrm{B}-\mathrm{O}$ bond stretching of the tetrahedral $\mathrm{BO}_{4}$ units.

Further, the bands in the spectral range of $1200-1400 \mathrm{~cm}^{-1}$ were produced by the asymmetric stretching vibration of the $\mathrm{B}-\mathrm{O}$ bond of the trigonal $\mathrm{BO}_{3}$ units in the various borate groups, such as the boroxol ring, diborane, metaborate, pyroborate, and orthoborate groups [45]. Furthermore, the existence of these bands confirmed the amorphicity of the investigated glass samples. The spectrum ranged of $1500-4000 \mathrm{~cm}^{-1}$ revealed the third group, which included several bands in part between 1500-1750, 2250-3000, and $3000-4000 \mathrm{~cm}^{-1}$; these bands might be due to the hygroscopic character of the powdered glass samples [46]. The absorption bands in the region of $3000-3750 \mathrm{~cm}^{-1}$ confirmed the existence of $\mathrm{H}_{2} \mathrm{O}$ and the $\mathrm{OH}$ groups within the glass network, which resulted in the formation of bridging bonds, such as $\mathrm{B}-\mathrm{H}-\mathrm{B}$ and $\mathrm{H}-\mathrm{O}-\mathrm{H}$. These bridging bonds generated the vibrational bands in the IR region of $1500-1750 \mathrm{~cm}^{-1}$. Furthermore, the bands at 2338 and $2370 \mathrm{~cm}^{-1}$ indicated the formation of a $\mathrm{BH}_{2}$ compound, which generally induces doublet bands, within the glass matrix. Finally, the bands at 2748,2854 , and $2934 \mathrm{~cm}^{-1}$ might be due to the vibrations of the hydrogen bonds [46].

Comparing the FTIR spectra of the BGCu-2.0 glass after its exposure to different irradiation doses (Fig. 22) and before irradiation (Fig. 23) revealed that the IR spectra of the irradiated glass exhibited consistent vibrational absorption bands around the same locations of the unirradiated glasses. Several researchers have demonstrated that subjecting glasses to high ionizing radiation, such as gamma and X-rays, would cause several fluctuations in their chemical and physical properties [47]. Gamma rays produced the absorption bands in several spectral ranges because of the formation of defect centres due to the capture of loose electron pairs and positive holes generated by gamma-irradiation operations.

Furthermore, some authors concluded that shielding occurs as the transition metals oxide-doped glasses are exposed to consecutive gamma-irradiation doses [48]. Moreover, the modification in the borate matrix might also be explained by the existence of an alkali oxide, which enhanced the polymerization of the borate matrix [49]. Additionally, the coordination of boron changes from trigonal to tetrahedral. After that, some of the basic borate units would change from $\mathrm{BO}_{3}$ into $\mathrm{BO}_{4}$ groups.

\subsubsection{DAT and calculation of $\mathrm{N}_{4}$ of the selected sample after irradiation}

To better understand the structural changes before and after irradiation, a deconvolution is performed (Figs. 22-24) to resolve all smearing bands caused by overlapping of triangular and tetrahedral borate groups with symbols $\left(\mathrm{BO}_{3}\right.$ and $\left.\mathrm{BO}_{4}\right)$, respectively. The percentage of $\mathrm{N}_{4}$ coordination can be calculated 
from such data and used to interpret FTIR data in relation to changes in bridging and non-bridging oxygen (BO and NBO).

Figs. 25(a and $b$ ) show the variation in the $\mathrm{N}_{4}$ coordination with varying $\mathrm{Cu}$ contents within the samples and the irradiation doses. It was clear that a change in the Cu content might cause a significant linear change in the four coordinated boron atoms $\left(\mathrm{N}_{4}\right)$ due to the variation in the number of nonbridging oxygens corresponding to the increasing $\mathrm{Cu}$ content. However, the irradiation process did not change the value of $\mathrm{N}_{4}$ as they only indicated the formation of defects or the rearrangement of the structural units.

\section{Conclusion}

In this work, the gamma-ray-shielding capacity of prepared glasses was measured via gamma spectroscopy and the Phy-X PSD software. We observed that the addition of $\mathrm{CuO}$ enhanced the shielding capacity; it increased $\angle A C / M A C$ and $Z_{\text {eff }}$ by reducing the HVL, MFP, and EABF values. These results demonstrated that the BGCU-4.0 sample offered superior gamma-ray protection compared with the other samples.

Further, the Cu ions-doped bioactive borate glass exhibited 2.5 times that of alanine due to the new preparation method, which improved the dose estimation at the radiotherapy level. Further, we recommend the utilization of this new material as an ESR dosimeter. Different methods, such as the replacement of metal $\mathrm{CuO}$, which allows the measurement of the gamma-radiation doses in the intermediate-dose range (2-200 Gy), was applied to enhance the sensitivity. In future works, we recommend using high linear energy transfer (high LET) radiation energy by doping modified glass with transition metals, especially in mixed radiation fields. The FTIR absorption spectra exhibited due to the distributions of the borate groups in triangular and tetrahedral BO3 and BO4 in their distinct wavenumber locations (1200-1600 cm-1 and 800-1200 cm-1, respectively remarkable vibrational peaks within the midmost area $\left(400-1600 \mathrm{~cm}^{-1}\right)$. The good dosimetric properties of such a modified material might make it a good candidate for the practical detection and monitoring of gamma-radiation doses.

\section{Declarations}

\section{Declaration of competing interest}

The authors declare that they have no known competing financial interests or personal relationships that could have appeared to influence the work reported in this paper

\section{Funding}

This research did not receive any specific grant from funding agencies in the public, commercial, or not for profit sectors. 


\section{Compliance with ethical standards}

There are no conflicts of interest about the present work that declare all relationships or interests of the manuscript's authors that could potentially influence or bias the submitted work.

\section{Research Data Policy and Data Availability Statements}

The data and material were available.

\section{Author contributions}

A. M. Madbouly: contributed in this study, Conceptualization, Methodology, Validation, Formal analysis, Investigation, Resources, Software, Data curation, Writing - original draft Writing - original draft, Writing - review \& editing Writing. F. M. Ezz-EIDin : contributed in this study, Methodology, Validation, Resources, Software, Project administration. A.M.Abdelghany : contributed in this study, Resources, Software, Formal analysis, Writing - original draft, Data curation. H. M. Diab: contributed in this study, Validation, Formal analysis, Investigation, Resources, Writing - original draft Writing - original draft.

\section{References}

1. Guo-hui W, Man-li He, Fan-chao C, Jun-dong F and Yao-dong D 2019 Prog Nucl Energy 112 225-32 https://doi.org/10.1016/j.pnucene.2019.01.001.

2. Elazaka Al, Zakaly HMH, Issa SAM, Rashad M, Tekin HO and Saudi HA Gillette V H, Erguzel TT and Mostafa AG 2021 J Hazard Mater 403123738 https://doi.org/10.1016/j.jhazmat.2020.123738

3. Diab HM, Abdelghany AM and Hafez HS $2020 \mathrm{~J}$ Materials Science: Materials in Electronics 1-8 https://doi.org/10.1007/s10854-020-04564-4

4. Abd-Elghany AA, Diab HM, Sulieman A $2020 \mathrm{~J}$ of Radiation Research and Applied Sciences 13 246-251 https://doi.org/10.1080/16878507.2020.1727676

5. Zavoisky E 1945 J Physics 9 245-249.

6. Marrale, M, Abbene L, d'Errico F, Gallo S, Longo A, Panzeca S, Tana L, Tranchina L and Principato F 2017 J Radiation Measurements 106:1-5 DOI:10.1016/j.radmeas.2017.03.009

7. Ye Liu, Lei Ma, Junwang Guo, Guofu Dong, Jianbo Cong, Yunlong Ji, Jing Ning, Guoshan Yang and Ke Wu 2018 PLoS ONE 13(5): e0197953 https://doi.org/10.1371/journal.pone.0197953.

8. Gallo Salvatore, lacoviello Giuseppina, Bartolotta Antonio, Dondi Daniele, Panzeca Salvatore and Marrale Maurizio 2017 Nuclear Inst. and Methods in Physics Research, B 407: 110-117 DOI:10.1016/j.nimb.2017.06.004.

9. Angela Kinoshita, Oswaldo Baffa and Sérgio Mascarenhas 2018 PLoS ONE 13(2): e0192444. https://doi.org/ 10.1371/journal.pone.0192444. 
10. Alex Romanyukha , Francois Trompier and Ricardo A. Reyes 2013 Radiation Environmental Biophysics DOI 10.1007/s00411-013-0511-8.

11. Duval M 2015 Radiation Measurements 79: 24-32 https://doi.org/10.1016/j.radmeas.2015.06.004

12. Chandkiram Gautam, Avadhesh Kumar Yadav, and Arbind Kumar Singh 2012 International ISRN Ceramics 428497-17 doi:10.5402/2012/428497

13. Anuchit Hunyek $2019 \mathrm{~J}$ of King Mongkut's University of Technology North Bangkok 29 DOI:10.14416/j.kmutnb.2019.03.008.

14. Bahaa H Rabee and Nasser Jabar 2017 Journal of Chemical and Pharmaceutical Research 9(5):310-314.

15. Aljawhara H Almuqrin and Sayyed MI 2021 Applied Science 11: 5697 https://doi.org/10.3390/app11125697

16. Parminder Kaur, K J Singh, Sonika Thakur, Prabhjot Singh and B S Bajwa 2019 Spectrochimica Acta Part A: Molecular and Biomolecular Spectroscopy 206:367-377. doi: 10.1016/j.saa.2018.08.038.

17. Ahmed MR, Phani AVL, Narsimha Chary M and Shareefuddin M 2018 AlP Conference Proceedings DOI: 10.1063/1.5032884

18. Abou Hussein EM , Madbouly AM , EzzEldin F M and El Alaily N A 2021 J Mater. Chem. Phys. 261 124212 DOI: 10.1016/j.matchemphys.2020.124212

19. Sallam OI, Madbouly AM, Elalaily N A and Ezz-Eldin F M 2020 J. Alloys Compds. 843 156056 https://doi.org/10.1016/j.jallcom.2020.156056

20. Madbouly AM , Alazab Huda A, Borham E and Ezz-EIDin F M 2021 J Applied Physics A 127 761.https://doi.org/10.1007/s00339-021-04889-9

21. Abou Hussein EM , Madbouly AM, and EzzEldin FM 2021 J Mater Sci: Mater Electron $3225933-$ 25951 https://doi.org/10.1007/s10854-021-05368-w

22. akar S, "Ozpolat E "OF, Alım B, MI Sayyed and Kurudirek M 2020 J Radiat. Phys. Chem. 166 108496. DOI: 10.1016/j.radphyschem.2019.108496.

23. Murat Kurudirek 2014 J Radiat. Environ. Biophys. 53 175-185 DOI: 10.1007/s00411-013-0502-9

24. Sayyed MI, Manjunatha HC , Gaikwad DK, Obaid SS , Zaid MHM. and Matori KA 2018 Dig. J. Nanomater. Bio. 13 701-712

25. Alajerami YS, D Drabold, Mhareb MHA, Katherine Leslee, Cimatu A, Gang Chen and Kurudirek M 2020 Ceram. Inter. 46 12718-12726 https://doi.org/10.1016/j.ceramint.2020.02.039

26. Tekin HO , Issa SAM , Kavaz E and AltunsoyGuclu EE 2019 J Mater. Res. Exp. 6 115212 https://doi.org/10.1088/2053-1591/ab4cb5

27. Yasser Saddeek B , Shams Issa AM , T Alharbi , Aly K, Mahmoud Ahmad and Tekin HO 2020 Ceram. Int. 463 2661-2669 https://doi.org/10.1016/j.ceramint.2019.09.254

28. Tekin, HO, Sayyed MI, Issa Shams A M 2018 Radiation Physics and Chemistry 150: 95100 https://doi.org/10.1016/j.radphyschem.2018.05.002 
29. Mahmoud KA, Lacomme E, Sayyed MI , Ozpolat OF and Tashlykov O L 2020 J Heliyon 6 e03560 https://doi.org/10.1016/j.heliyon.2020.e03560

30. Tekin HO , Erguzel TT, Sayyed MI, Singh VP, Manici T, Altunsoy EE and Agar O 2018 Dig. J. Nanomater. Bio. 13 381-389

31. Seenappa L, Manjunatha H C , Sridhar K N and Chikka Hanumantharayappa 2018 Indian J. Pure Appl. Phys. 56 383-391

32. Al-Buriahi MS, Abouhaswa AS, Tekin HO , Sriwunkum C , El-Agawany FI, Nutaro T ,Kavaz E , and Rammah YS 2020 Ceram. Int. 46, 1711 https://doi.org/10.1063/5.0053029

33. El Abd A, Gamal Mesbah, Nader M. A. Mohammed and Ellithi A 2016 Journal of Radiation and Nuclear Applications 2:53-58 http://dx.doi.org/10.18576/jrna/020203

34. Abdelghany AM, ElBatal HA and EzzEIDin FM 2015 Spectrochimica Acta Part A: Molecular and Biomolecular Spectroscopy 149:788-792 DOI:10.1016/j.saa.2015.04.105

35. Chow JCL 2016 Springer International Publishing, Cham 41-65 DOI: 10.1007/978-3-319-153384_10

36. Gallo S, lacoviello G, Bartolotta A, lacoviello G, Bartolotta A, Dondi D, Panzeca S and Marrale M 2017 Nuclear Instruments and Methods in Physics Research, Section B: Beam Interactions with Materials and Atoms. https://doi.org/10.1016/j.nimb.2017.06.004.

37. Gautam C, Yadav AK and Singh AK 2012 ISRN Ceramics. https://doi.org/10.5402/2012/428497

38. Fatma H. Margha and Amr M. Abdelghany 2012 Processing and Application of Ceramics $6: 4: 183-$ 192 DOI: 10.2298/PAC1204183M

39. Sherald H Gordon, Rogers E Harry-O'kuru and Abdellatif A Mohamed 2017 Talanta 174: 587-598 DOI: 10.1016/j.talanta.2017.06.043

40. Christian Menno Mu“ller, Bobby Pejcic, Lionel Esteban, Claudio Delle Piane, Mark Raven and Boris Mizaikoff 2014 Scientific reports 4:6764 DOI: 10.1038/srep06764

41. Rimma Bubnova, Sergey Volkov , Barbara Albert and Stanislav Filatov 2017 Crystals 7: 93 doi:10.3390/cryst7030093

42. Menazea AA, Abdelghany AM, Hakeem NA, OSMAN WH and ABD EL-KADER FH $2020 \mathrm{~J}$ Electronic Materials 49:826-832 https://doi.org/10.1007/s11664-019-07736-z

43. Winterstein-Beckmann Anja, Möncke Doris, Palles Dimitrios, Kamitsos Efstratios and Wondraczek Lothar 2015 Journal of Physical Chemistry B 119(7):3259-3272 DOI:10.1021/jp5120465

44. Halimah MK, Chiew WH, Sidek HAA, Daud WM, Wahab ZA, khamirul AM and Iskandar SM 2014 Sains Malaysiana 43:899-902

45. El Batal HA, Abou Hussein EM, El Daily NA, EzzEldin FM 2020 J Non-Crystalline Solids 528:119733 DOI: 10.1016/j.jnoncrysol.2019.119733

46. M.A.Z E 2020 SYLWAN 164:513-531.

47. ElBatal FH, Ibrahim S and Abdelghany AM 2012 J Molecular Structure 1030:107112 DOI: $10.1016 /$ j.molstruc.2012.02.049 
48. Menazea AA, Abdelghany AM 2020 Radiation Physics and Chemistry 108932 DOI: 10.1016/j.radphyschem.2020.108932

49. Abdelghany AM and Behairy A $2020 \mathrm{~J}$ Materials Research and Technology 9:1049110497 https://doi.org/10.1016/j.jmrt.2020.07.057.

Figures

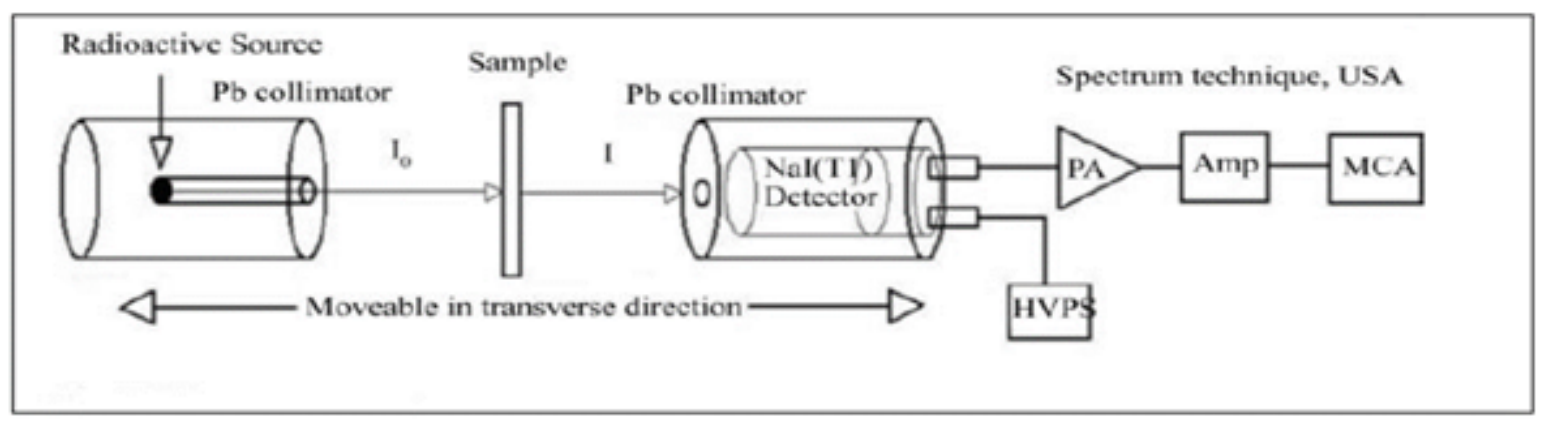

Figure 1

Experimental setup for the gamma-ray spectrometer.

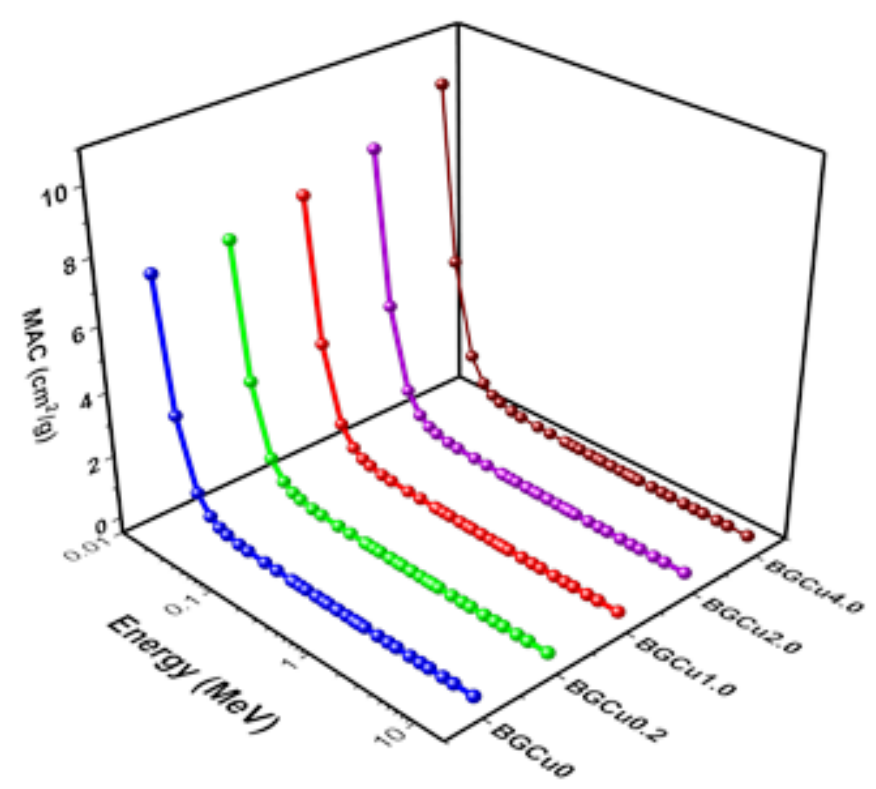

\section{Figure 2}

The MAC verses the concentration of $\mathrm{CuO}$ composites 


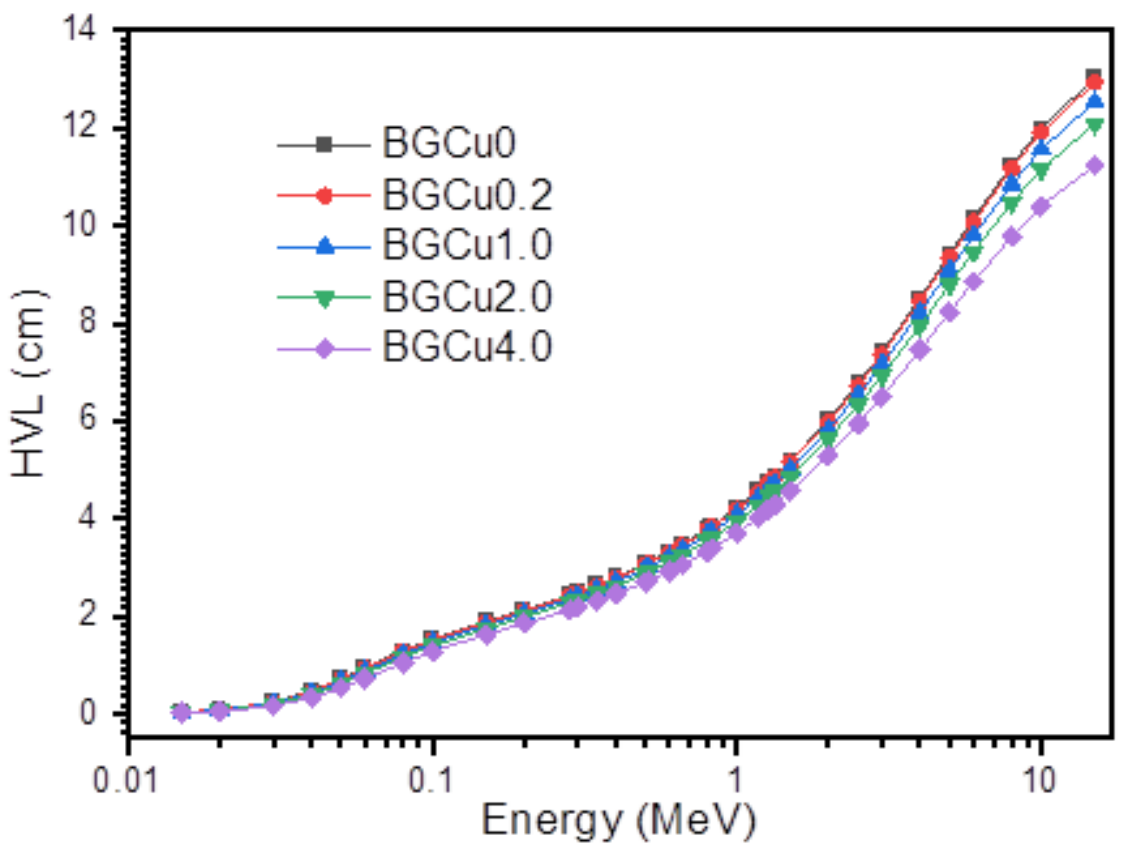

Figure 3

The variation of $\mathrm{HVL}$ with energy for all studied glasses . 


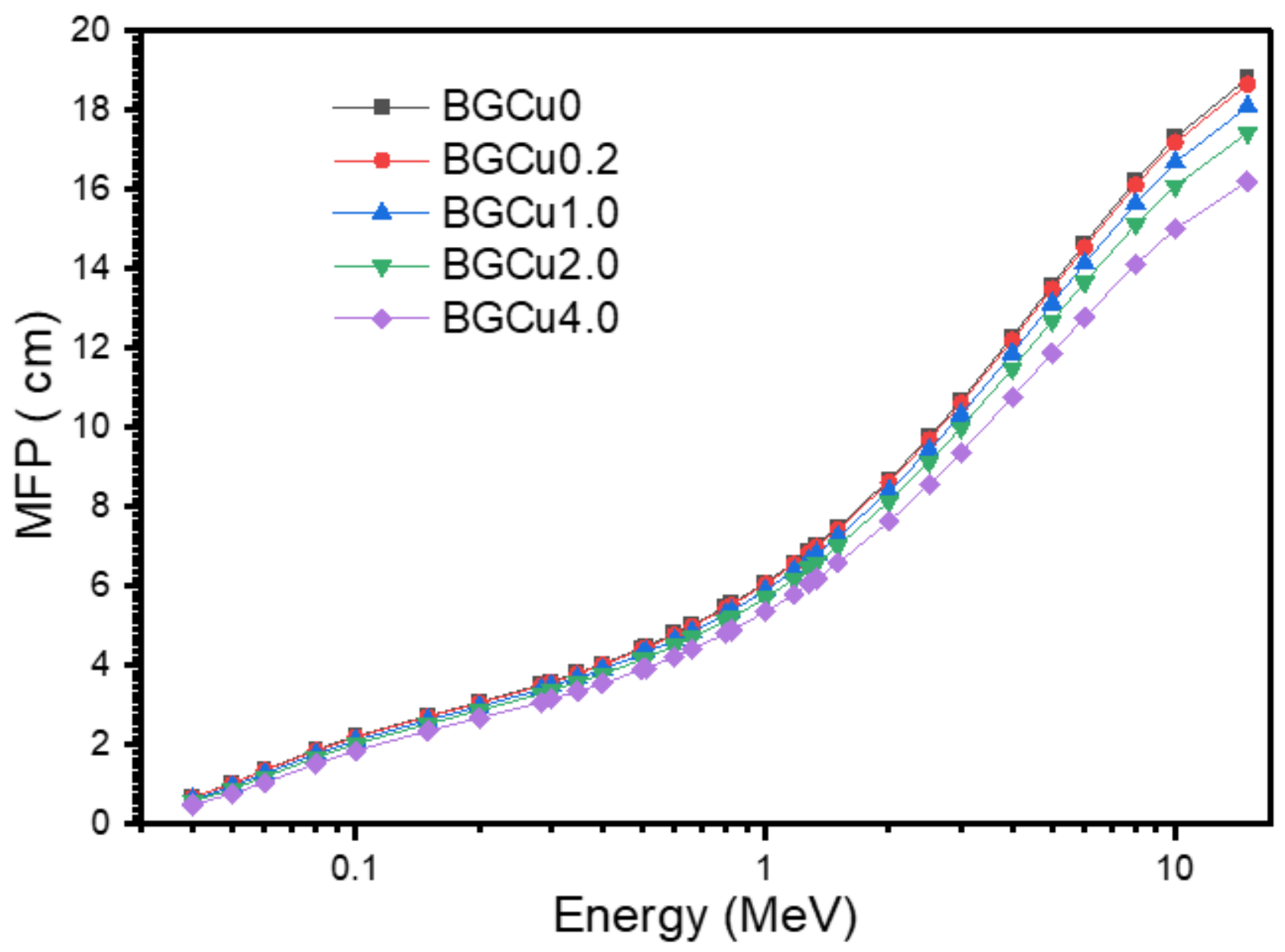

Figure 4

The variation of MFP with energy for all studied glasses.

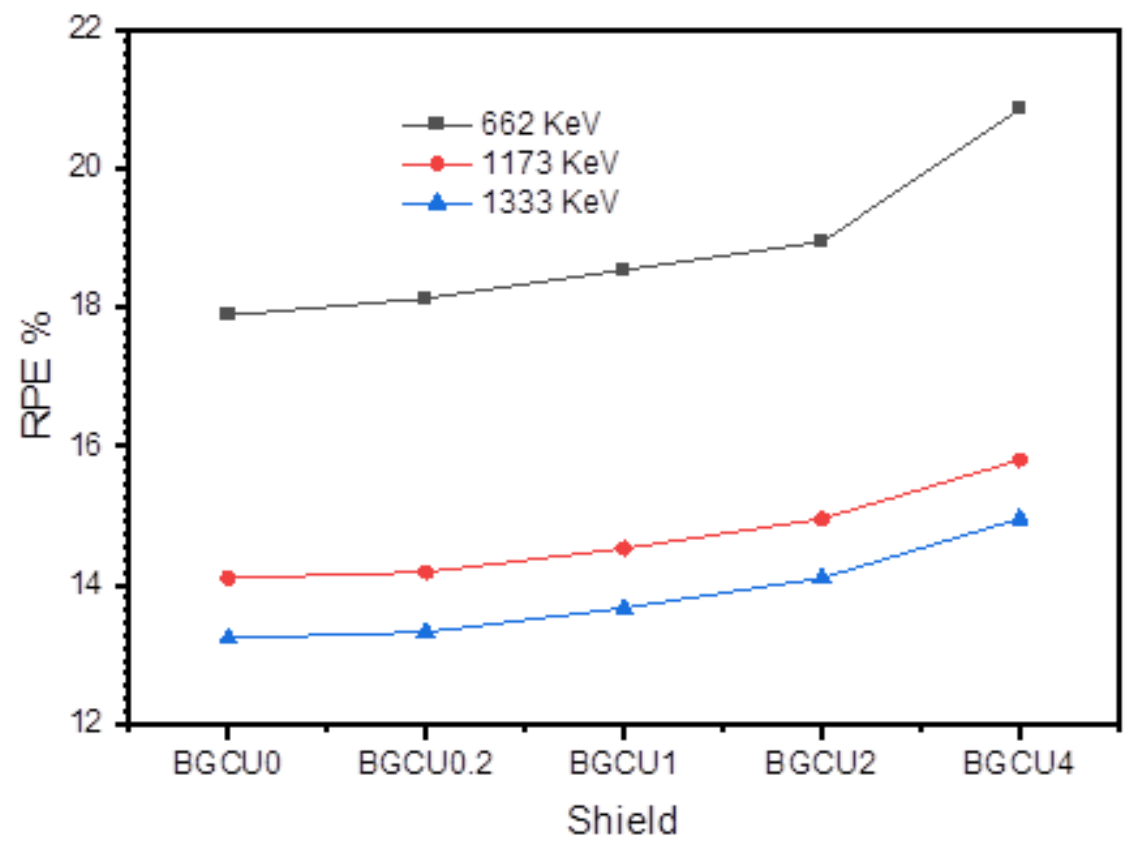


Figure 5

Radiation protection efficiency (RPE\%) for different concentrations of $\mathrm{Cu}$. .

\section{Figure 6}

Variation of effective atomic number $Z_{\text {eff }}$ with energy for all samples with different concentrations of $\mathrm{Cu}$

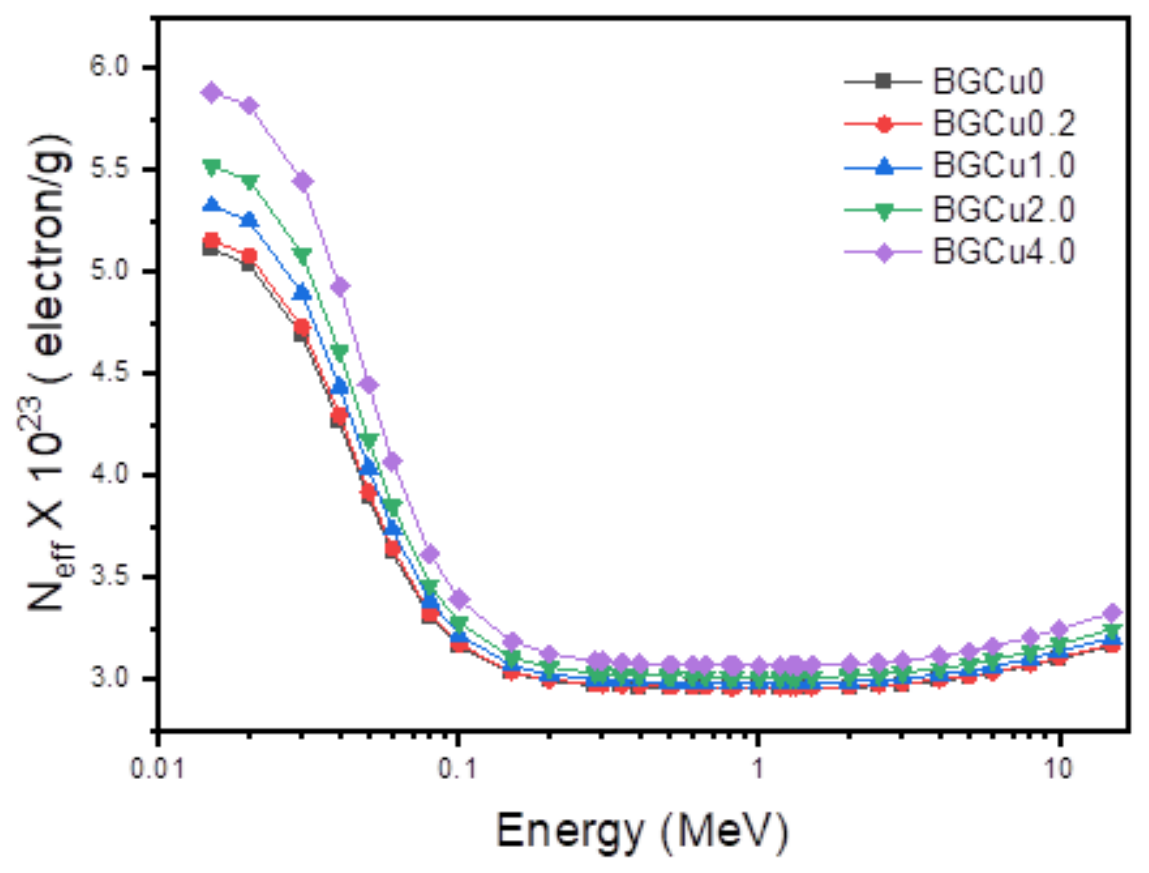

Figure 7

Variation of effective electron density $\mathrm{N}_{\text {eff }}$ with energy for all samples with different concentrations of $\mathrm{Cu}$

\section{Figure 8}

Variation of effective conductivity $C_{\text {eff }}$ with energy for all samples with different 


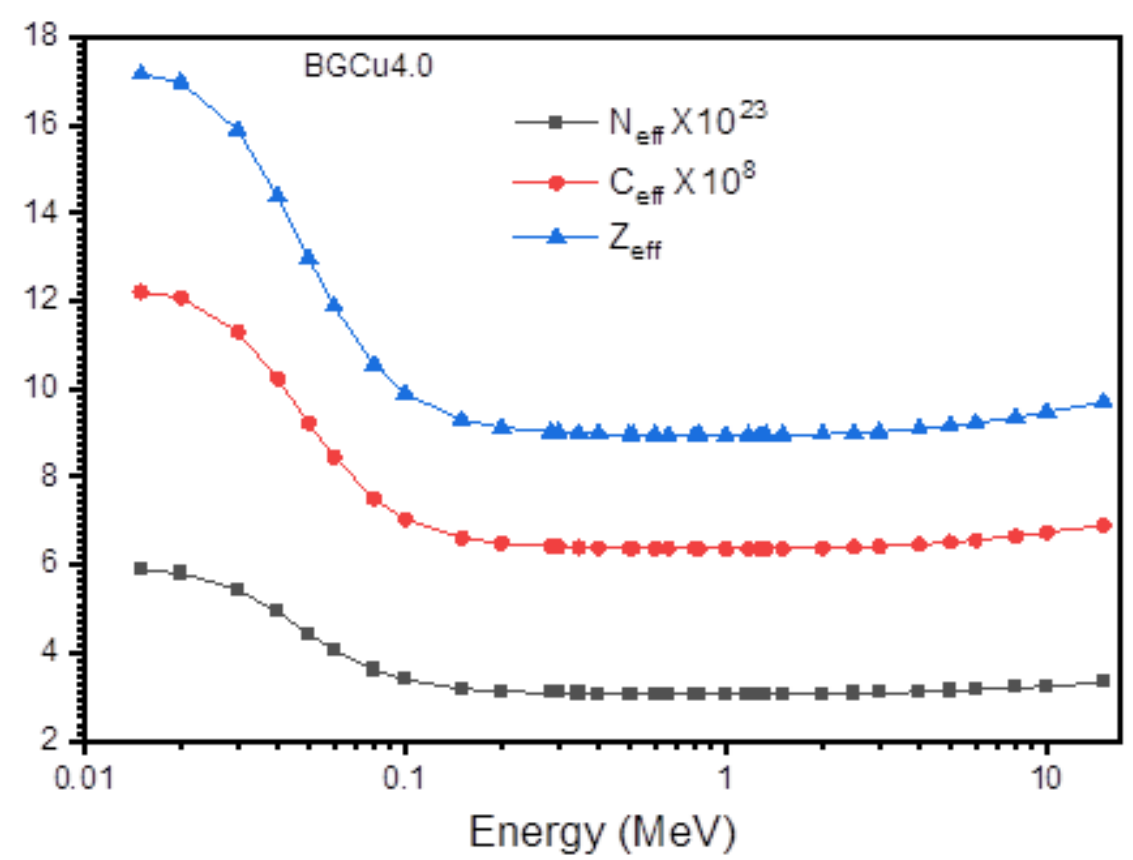

Figure 9

Relation between $\mathrm{Z}_{\text {eff }}, \mathrm{N}_{\text {eff }}$ and $\mathrm{C}_{\text {eff }}$ with energy for BGCU4.0 sample.

Figure 10

(a-d) Variations of energy absorption build-up factor (EABF) with photon energy at different mean free paths for all glasses. 


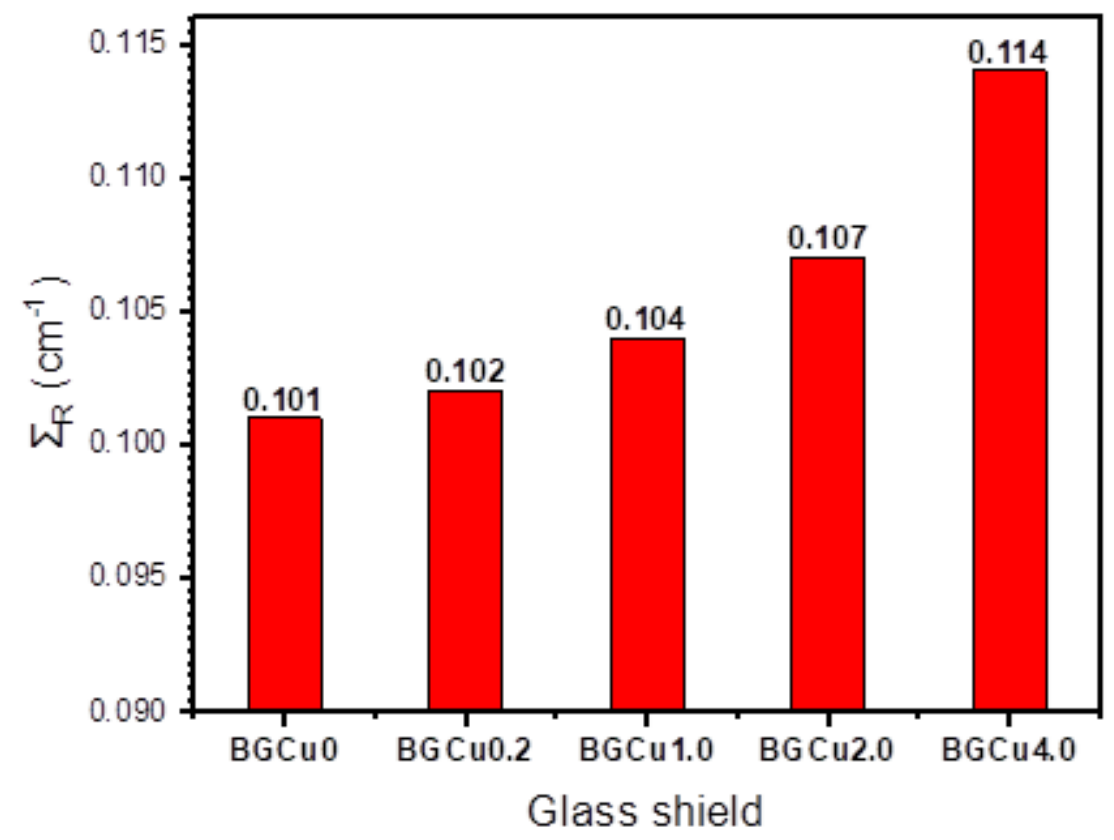

Figure 11

Effective removal cross-sections for fast neutrons $(\Sigma R)$, for all glasses.

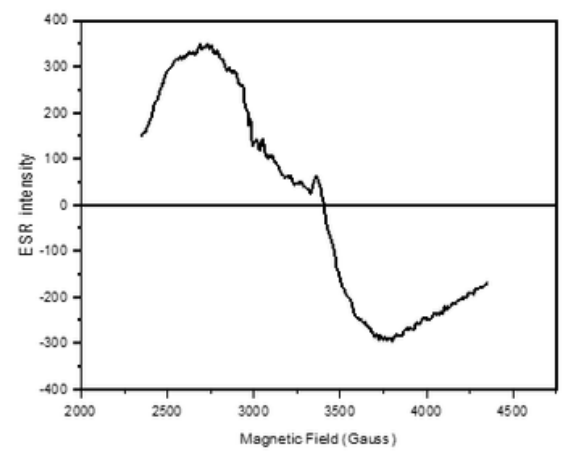

(a)

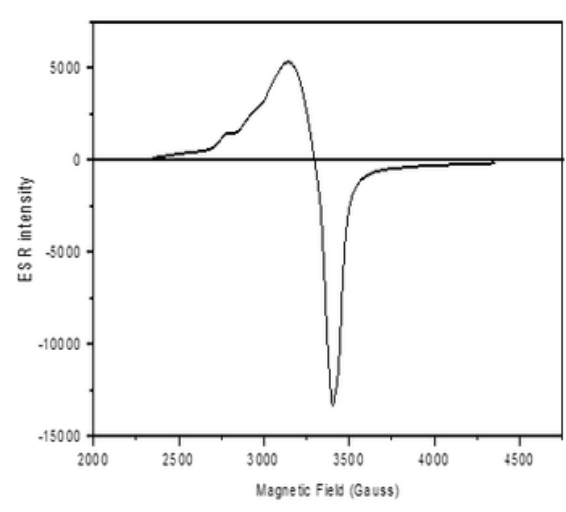

(b)

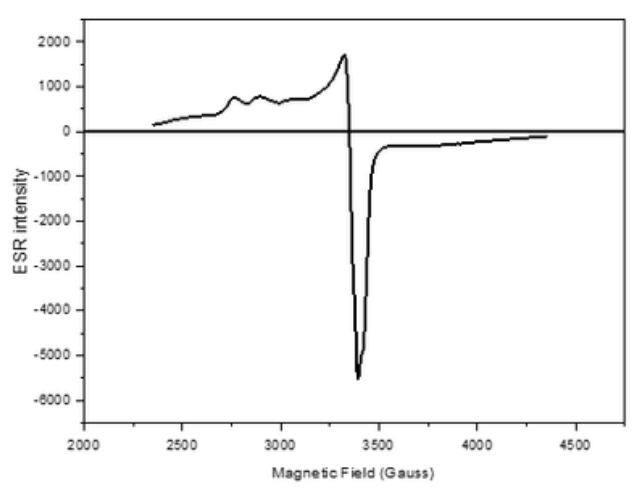

(c)

Figure 12

Typical ESR spectra of (a) parent glass (b) selected copper doped sample before irradiation process and (c) after being irradiated with $200 \mathrm{~Gy}{ }^{60} \mathrm{Co}$ gamma ray. The sweep width of magnetic field was $4000 \mathrm{G}$.

Figure 13

200 Gy Gamma rays irradiated dosimetric signal (1 scan) based on Microwave power dependency. 
Figure 14

Dose response relationship for samples and alanine as a function of the dose from Co-60 source (10 scans)

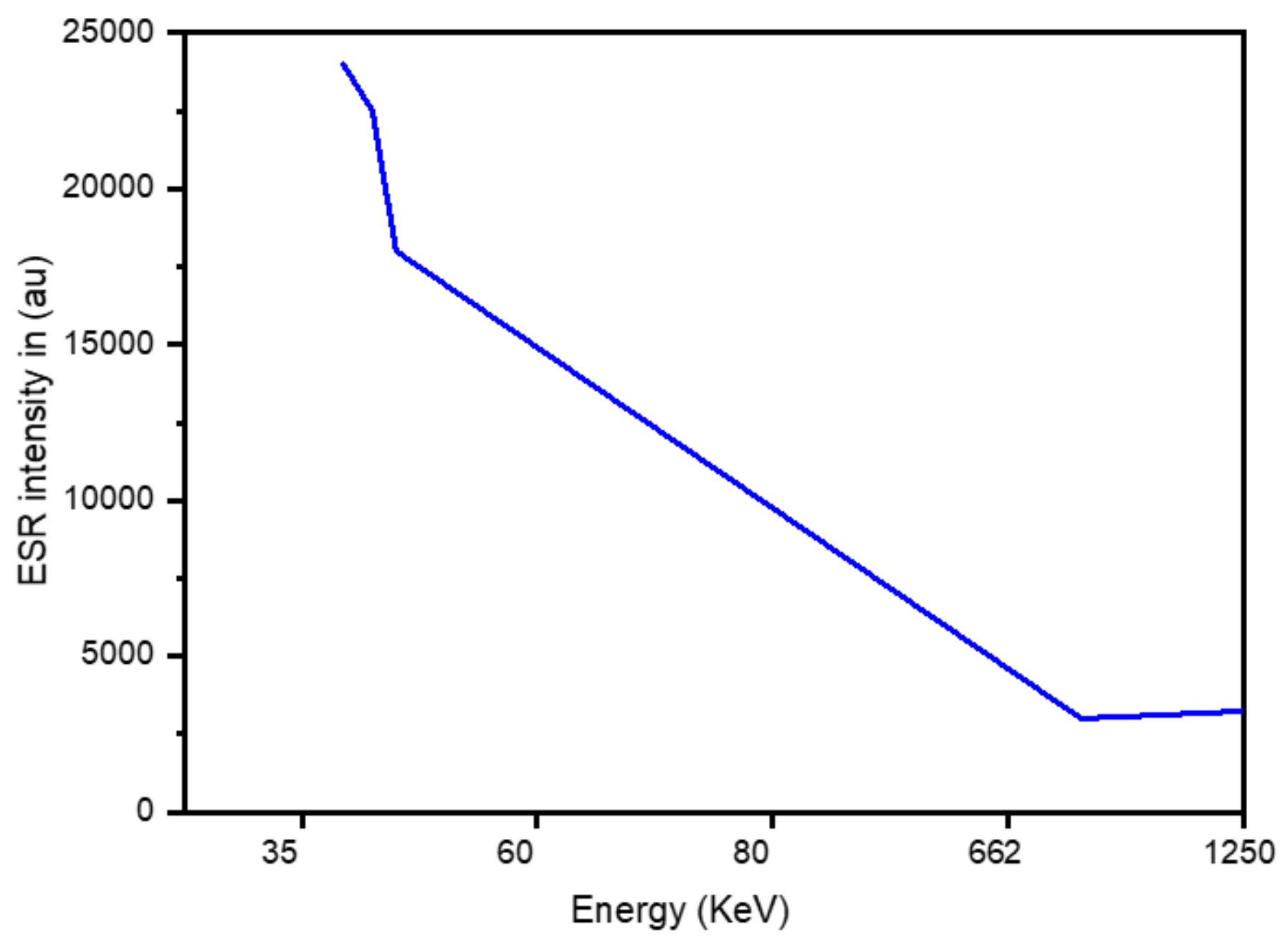

Figure 15

Energy dependent of ESR intensity of borate bioactive glass (a.u)

Figure 16 
Signal to noise ratio for alanine and borate bioactive glass

\section{Figure 17}

Isochronal annealing of samples which is ranging from $25^{\circ} \mathrm{C}$ up to $200{ }^{\circ} \mathrm{C}$ certain temperature and the relative intensity(n/no) of the dosimetric signal corresponding to certain temperature

\section{Figure 18}

Isothermal annealing study of borate bioactive glass based on time dependency and to second order decay $(1 / n)$

\section{Figure 19}

shows isothermal annealing in borate bioglasses and from Lifetimes versus $(1000 / T)$ which represent the reciprocal temperature experiments. At room temperature, estimation of the straight line gives the lifetime. 


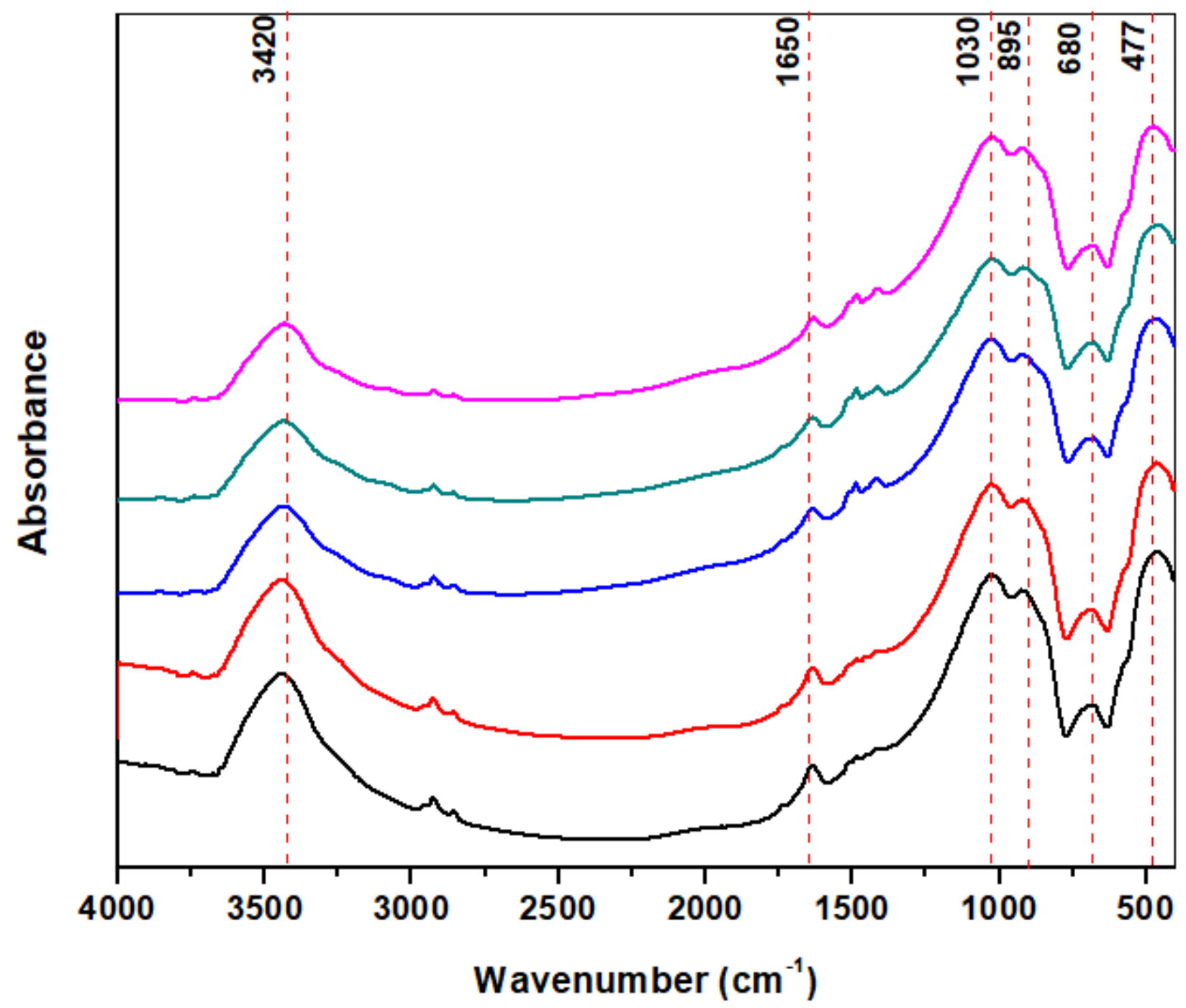

Figure 20

FTIR absorption spectra of synthesized glasses before irradiation.

\section{Figure 21}

FTIR absorbance of the investigated glass after irradiation

\section{Figure 22}

Deconvolution of FTIR absorbance peaks of the investigated glass before irradiation 
Figure 23

An exemplified deconvolution analysis of sample that contain 1\% Copper oxide before irradiation

\section{Figure 24}

Deconvolution of FTIR absorbance peaks of the sample containing $1 \% \mathrm{CuO}$ after irradiation

\section{Figure 25}

$(a, b)$ Variation of the four-coordinated boron as a function of copper oxide concentration and irradiation doses. 